\title{
Diplomacias cosmopolíticas e os desafios da linguagem: perspectivas das terras baixas sul-americanas
}

\author{
PAOLA GIBRAM \\ UNIVERSIDADE DE SÃO PAULO (USP), SÃO PAULO/SP, BRASIL \\ HTTPS://ORCID.ORG/0000-0003-4369-8675
}

MARINA VANZOLINI

UNIVERSIDADE DE SÃO PAULO (USP), SÃO PAULO/SP, BRASIL

HTTPS://ORCID.ORG/0000-0002-6245-7650

RENATO SZTUTMAN

UNIVERSIDADE DE SÃO PAULO (USP), SÃO PAULO/SP, BRASIL HTTPS://ORCID.ORG/0000-0003-387I-4984

Em 2018, durante o seminário "Lições de fala: diálogos ameríndios", que reunia na USP pesquisadores indígenas de diferentes partes do Brasil, Maria José Katxuyana, depois de escutar atenta ao debate sobre as dificuldades da tradução do termo "política” para diferentes línguas indígenas, interveio discretamente: "política é, para nós Katxuyana [falantes de uma língua karib], wotuno”. Em seguida, ela explicou que wotuno poderia ser também traduzido como "conversa", "diálogo" e também "reunião". Lideranças seriam aquelas que fazem wotuno, que sabem falar, que criam falando. A solução de Maria José Katxuyana foi bem recebida pelos demais participantes indígenas, que logo ofereceram exemplos análogos.

O lastro entre política e linguagem, aqui evidenciado, foi vislumbrado na América indígena por antropólogos como Robert Lowie e Pierre Clastres². E não podemos esquecer que ele se faz notar também na fundação da filosofia política ocidental. Em A Política, Aristóteles associava o Logos, o discurso articulado, ao discernimento entre o justo e o injusto e à capacidade de inferir o "bem comum". Oposto

1 Para mais elementos sobre o wotuno kaxuyana, ver Luísa Girardi (2019).

2 Para um estudo pioneiro sobre a relação entre poder e uso da linguagem em povos de diferentes partes do mundo, ver a coletânea de Maurice Bloch (1975). 
ao Logos, propriamente humano e aliado da Razão, estaria o Phoné, a voz física, marca de animalidade. Jacques Rancière recupera a distinção de Aristóteles, mas para atentar que as condições de mútua inteligibilidade pela linguagem não estão dadas e que a política se define pelo desentendimento. "Há política", escreve ele, "quando os que têm direito de serem considerados como seres falantes se fazem considerar e instauram uma comunidade" (1995: 49).

Para estender a formulação de Rancière ao mundo indígena seria preciso alargar o sentido daquilo que chamamos de diálogo, fala, conversa e linguagem, considerando suas modalidades e suas modulações. Se há política quando os que têm direito de serem considerados como seres falantes se fazem considerar, devemos perguntar: o que é um ser falante? Quem se considera e é considerado como tal? Falar seria um atributo exclusivamente humano? Mas o que é realmente o humano aí? O que implica nessas paisagens essa instauração de comunidades? Como intuiu Pierre Clastres (1974a, 1974b), especialmente em suas reflexóes sobre os Guarani, o projeto de antropologia política ganha quando deparado com o problema das metafísicas indígenas da palavra, estas que põem em risco fronteiras ontológicas e dizem respeito menos à representação que a constituição de mundos ${ }^{3}$. Como insistiram Isabelle Stengers (2007) e Bruno Latour (2007) - pensando sobre os modernos, muitas vezes sob o efeito de textos sobre os "não-modernos" - é preciso inserir na política problemas que a filosofia política moderna aprendeu a descartar, isto é, de que há política também no que se convencionou chamar de natureza, naquilo que é objeto das ciências. Em suma, há de se pensar a dimensão cosmopolítica de toda política, e nesse ponto não se poderia deixar de lado o problema da linguagem.

Todas essas questões atravessam os textos do dossiê Diplomacias cosmopolíticas e os desafios da linguagem: perspectivas das terras baixas sul-americanas. Parte dos autores ora reunidos, dentre os quais os organizadores deste dossiê, integraram o projeto "Diplomacias cosmopolíticas nas terras baixas sul-americanas: exercícios de comparação etnográfica”. ${ }^{4} \mathrm{O}$ termo "diplomacia" também foi tomado emprestado dos textos de Stengers e Latour: diplomacia que se estabelece em meio a uma "guerra de mundos" e que portanto exige que seja posta em risco a ideia de um mundo único, de uma natureza comum e imutável. "Diplomacia cósmica" é como Viveiros de Castro (2002) se refere aos xamanismos indígenas, estes que operam o trânsito por entre mundos (multi-naturezas) e corpos diversos. Nosso intuito era tomar não apenas os xamanismos em termos de diplomacias cosmopolíticas, mas também outras formas de relações e eventos, como festas, trocas, diálogos cerimoniais etc., considerando que todas essas instâncias compreendiam encontros entre mundos e, portanto, se viam carregadas de incerteza ontológica. Concentramo-nos, enfim, em eventos diplomáticos marcados pela circulação de palavras; por exemplo, práticas de nominação, falas de chefe e de aconselhamento, diálogos cerimoniais, interações mediadas por cantos, admitindo de partida que a linguagem aí empregada não poderia ser descrita nos termos modernos da representação. Compreendida em seus próprios termos, essa linguagem estaria

3 O problema das "ideologias linguísticas" ou das "metafísicas da linguagem" tem sido alvo de trabalhos inovadores tanto na antropologia como na linguística. Não há espaço aqui para remontar a eles. Por ora, destacamos alguns trabalhos, que foram fundamentais para a nossa reflexão: Silverstein (1990), Rumsey (1990), H. Clastres (1975, 2011), Farage (1997), Graham (1995), Cesarino (2011, 2013), Kelly (2017), Severi \& Bonhomme (2009), Deleuze \& Guattari (1980), Course (2010, 2011, 2018), Hauck \& Heurich (2018), Hauck (2018), Heurich (2018).

4 Agradecemos à Fapesp pelo financiamento deste projeto de pesquisa, vigente entre março de 2016 e setembro de 2018. O projeto teve Renato Sztutman como pesquisador responsável. 
mais próxima de um fazer: fazer mundos, fazer coletivos, fazer pessoas. Esse caminho nos conduziu, em suma, de uma antropologia da política indígena às teorias indígenas da linguagem - não sem passar pela contra-antropologia indígena da política e da linguagem dos não-indígenas.

Como etapa de conclusão do projeto, organizamos, em julho de 2018, o Seminário "Lições de fala" (acima mencionado $)^{5}$, que reuniu dezoito pesquisadores indígenas e dezessete não indígenas para debater "o que falar quer dizer" a partir de suas diferentes experiências e perspectivas: discursos de lideranças, diálogos cerimoniais, cantos, narração de histórias, rumores transcorridos seja em momentos cotidianos, seja em eventos festivos. Para este dossiê, convidamos alguns dos palestrantes do seminário para publicar suas apresentações ou pesquisas correlatas, bem como pesquisadores que não participaram do encontro, mas têm desenvolvido contribuições altamente relevantes para a questão que nos colocamos.

No artigo que abre este dossiê, "Língua(s): cosmopolíticas, micropolíticas, macropolíticas”, Bruna Franchetto evidencia uma dimensão política da linguagem e das línguas para além - e aquém - dos seus usos na ação política: trata-se de ressaltar como a aniquilação da diversidade linguística "produz miséria, desigualdades e profundo mal-estar de quem é obrigado a se esconder atrás de uma língua dominante e dominadora”. Colocando em diálogo perspectivas da linguística e dos povos indígenas sobre os sentidos e a potência da língua, a autora faz uma defesa vigorosa da diversidade e da luta a ser travada para que a multiplicidade não sucumba ao monolinguismo, essa outra faceta da dominação colonial. Atenta às equivocações inerentes aos trânsitos tradutivos interlinguísticos, Franchetto ressalta não ser necessário haver nos vocabulários indígenas uma palavra relativa à "língua" para que as populações reconheçam seu modo próprio de falar como "língua" (problema análogo ao que destacamos acima sobre a dificuldade de traduzir o termo "política"). Este seria um dos motivos para que o Censo 2010 chegasse ao número de 274 línguas faladas no Brasil - considerado um tanto espantoso para os taxonomistas da linguagem. Franchetto traz então algumas expressões lexicais metalinguísticas encontradas no kuikuro (língua alto-xinguana da família karib) que sinalizam tais equivocações: expressões que apontam para o dizer, para os atos de fala, para o problema da distinção entre humanos e extra-humanos, e que não necessariamente traduzem-se como "língua". Estes sentidos, destaca a autora, conduzem para outra direção ou, em suas palavras, para a "margem ameríndia da pragmática” - aquela justamente do fazer e da eficácia inerentes às falas indígenas.

Franchetto pontua que as equivocações referentes a este campo de questões encontram amplo espectro de expressões nas mais diferentes línguas indígenas. Traz como exemplo os termos nhe'é e aywu dos Guarani Nhandeva e Guarani Mbya, cuja variabilidade de sentidos aponta justamente para os limites da apreensão tradutiva. É justamente sobre estes termos - nhe'é e aywu - que o artigo de Sandra Benites se detém. Apontando semelhanças e contrastes nos usos feitos pelos Guarani Nhandeva e pelos Guarani Mbya, a autora, que é conhecedora de ambas as variantes linguísticas, explora os muitos sentidos evocados por estes dois termos, dentre os quais destaca, de início, espírito, ser, vida, palavras, falas, som.

5 O título faz referência ao capítulo "Lição de escrita", de Tristes Trópicos (Lévi-Strauss 1955). Para Lévi-Strauss, os Nambikwara nos ensinam sobre algo fundamental para o nosso mundo, a escrita. Aqui buscamos ensinamentos sobre algo que os povos indígenas cultivam como ninguém - a fala - apostando que isso lance luz sobre algo que é também muito "nosso" - a política, a polis - mas sobre o qual podemos buscar analogias entre "eles". 
Benites apresenta a distinção entre os campos semânticos cobertos pelos termos aywu e nhe'e nas falas Nhandeva e Mbya, sem com isso enrijecer as diferenças. Assim, explica, entre os Guarani Mbya o termo aywu é associado à fala comum, cotidiana, enquanto nhe'é aponta para o plano do que chama de "espiritual" (o mundo das divindades celestiais): seriam as falas usadas nas casas de reza, ou ainda aquelas utilizadas para remeter às origens dos nomes e seus significados. Já entre os Nhandeva, tais associações dar-se-iam de modo inverso: aywu seria o termo associado ao plano do "sagrado" e nhe 'é, à fala comum. A oposição, no entanto, possui algumas particularidades: Benites destaca, por exemplo, que nhe 'e é também "palavra sagrada" entre os Nhandeva quando usada para se referir a um "ser espírito" ou "ser pessoa". Nhe'é seria, portanto, utilizado da mesma forma pelos Mbyá e pelos Nhandeva nos casos de referência à pessoa, ao ser, ao espírito, aos sentimentos. Estes, ligados às falas - sejam elas boas, ruins, jocosas ou sagradas -, localizam-se no $p y^{\prime}$ a, parte do corpo que remete "ao que fica no peito". A fala é, portanto, corpo, bem como parte constitutiva da pessoa: nhe 'é porã ou aywu porã, a boa fala, é fundamental para o ser guarani. Segundo Benites, é ela que traça um caminho (tape) para a construção de cada passo da pessoa, "lembrando-o sempre do coletivo" - linda forma de dizer que nenhum caminho é solitário, nenhuma pessoa deve se esquecer das demais. Micropolítica de produção de pessoas indistinguível da política entendida como processo de formação de coletivos e de uma cosmopolítica que toma a linguagem como modo de trânsito entre o mundo humano e o dos seres celestiais.

A labilidade semântica de certos termos, para a qual Benites chama a atenção na primeira parte do texto, parece colocar em jogo os temas da interpretação e da tradução. Pois não basta ouvir belas palavras, lembra a autora, é preciso saber entendê-las, ser capaz de compreender "seus significados, e sobretudo potências de sentido" - um desafio de interpretação, ela observa, que não se coloca apenas aos não-falantes da língua. Daí que a formação da pessoa Guarani não depende apenas da transmissão de ensinamentos, mas também da convivência, da experiência compartilhada, que conduz cada um ao melhor entendimento daquilo que escuta, assim como à capacidade de transmitir com suavidade, no futuro, aquilo que aprendeu. Nas belas palavras de Benites: "Falar nem sempre é falado: é apenas vivido, sentido, experimentado".

A constituição de pessoas e coletivos, ou pessoas-coletivas, através das falas de aconselhamento é também tema do artigo de Paola Gibram sobre os Kaingang. Gibram analisa os vênh jyvẽn, falas formais com alto conteúdo moral, que mobilizam recursos semânticos e gramaticais da língua kaingang dominados apenas por alguns especialistas, e que as tornam falas de grande beleza, como também de grande eficácia. Se esse tipo de aconselhamento reproduz, no plano do conteúdo, uma relação tipicamente doméstica (a orientação cotidiana dos mais novos pelos mais velhos da família), o fato de realizar-se em situações públicas o aproxima das falas do chefe para seu grupo, das quais se diferencia, por outro lado, por se dirigir sempre a uma pessoa por vez: no ato de fala, o conselheiro se mantém de pé, ereto, enquanto o aconselhado baixa a cabeça em sinal de respeito. Em consonância com o que Benites nos indica a respeito dos Guarani, a observação de Gibram permite situar num contínuo doméstico-público aconselhamentos familiares, aconselhamentos proferidos por especialistas e falas do chefe ao seu coletivo, entendidos em termos de uma diferença de escala mas não de natureza. Em cada contexto, trata-se de reafirmar as diferenças significativas (dentre as quais destacam-se a exogamia de metades e a 
oposição entre vivos e mortos) para os coletivos kaingang, reatualizando a ordem interna que garante a resistência do modo de ser kaingang. Não à toa, o sistema de aconselhamento está, entre os Kaingang, diretamente associado ao particular "sistema jurídico" local, que mobiliza uma espécie de "polícia" nativa a serviço do respeito às "leis internas".

Como revela Gibram, essas falas formalizadas que, à semelhança do que se passa em outros lugares, são caracterizadas pela obliteração do indivíduo emissor, estão via de regra apoiadas no conhecimento dos antigos, na mitologia. Mas não só. Seguindo seus professores kaingang, a autora enfatiza que os aconselhamentos devem abranger planos extra-humanos, exigindo que se aprenda a ouvir os seres da mata, tanto quanto se ouvir os mais velhos na infância e juventude. O pãa (líder, chefe) deve conhecer tanto o mato como o mito. Foi precisamente a importância desse exercício de escuta que D. Gilda Kuitá, liderança kaingang da TI Apucarana, explicou para os não-indígenas que participaram do seminário "Lições de Fala” - impelindo-nos “a ouvir mais, perguntar menos e ser mais respeitoso" - numa palestra que tomou a forma de um aconselhamento, como nota Gibram. Silêncio atento do aprendiz que nada tem a ver com as práticas de silenciamento impostas aos Kaingang pelo SPI, como lembra Dona Gilda, obrigando-os a abandonar as técnicas de que dispunham para garantir a manutenção do seu mundo: as palavras dos xamãs, cantos rituais, saberes dos anciãos, e mesmo as vozes dos conselheiros. É preciso então reconhecer os aconselhamentos kaingang, conclui Gibram, como falas resistentes e de resistência, "falas que criam vínculos com a floresta, que verticalizam as relações com os antepassados, que vivenciam e revelam memórias, tantas vezes ocultadas em contextos de contato mais intenso e violento com os fóg (não-indígenas)”.

Reencontramos o tema dos aconselhamentos - e logo a questão da passagem da política de produção de pessoas à produção de coletivos - no artigo de Aline Aranha sobre os nhemongueta mbya. Particularmente interessada na agência política feminina, Aranha enfoca o papel decisivo das mulheres nos aconselhamentos cotidianos, vislumbrando o que denomina como "diplomacias cosmopolíticas domésticas”. A forma mínima do aconselhamento é, em todos os exemplos citados, a da relação entre avós e netos, de ambos os sexos. Mas a autora também ressalta que a ação das mulheres não se limita à domesticidade, lembrando a crescente visibilidade de lideranças femininas fora das aldeias, e a atuação contínua das mulheres na casa de reza $(o p y)$. Vale lembrar que em guarani mbya os mesmos termos - xeramoi e xejaryi - designam genericamente todos os anciãos que figuram na posição de avós, e são usados especificamente para indicar homens e mulheres que se destacam como líderes espirituais, detentores de "palavras inspiradas". É fundamental ressaltar, escreve Aranha, a importância da complementaridade do casal xamã-conselheiro, xeramoi e xejaryi. Seus aconselhamentos ensinam a agir controladamente e evitar a desmedida que pode culminar em devires-animais (jepota) por vezes irreversíveis. Também ressurge aqui a ideia de que o aconselhado deve se colocar "em escuta" (-japyaxaka) e alcançar a concentração necessária para que, nos termos mbya, "a palavra entre no coração".

As lideranças espirituais - homens e mulheres, xeramoi e pela xejaryi - não apenas aconselham, mas também são responsáveis pela nomeação de pessoas. Eles são, em suma, aqueles que detêm com maior destreza o dom da palavra, manejando suas diferentes modalidades e modulações: sabem dar nomes, rezar, cantar e aconselhar. $\mathrm{O}$ artigo de Aranha retoma assim o tema clássico da relação entre 
nominação e teoria da palavra e da pessoa entre os Guarani Mbya. Os nomes mbya fazem pessoas, são eles que unem a "alma-palavra" (Cadogan 1959) ou a "linguagem-afeto"(Macedo 2009) - traduções possíveis para o termo complexo nhèe (que já encontramos no artigo de Benites) - ao corpo (bete). Chegado o momento da nomeação, xeramoi ou xejaryi devem buscar o nome da criança nos diferentes patamares celestiais. Estes "nomes-espíritos", contidos num repertório finito, estão associados a "caminhos-iluminações”. Dialogando com diferentes guaraniólogos, Aranha resume que nomes consistem em capacidades-poderes que habitam a pessoa, trazendo consigo saberes referentes à sua morada de origem, cada qual dotada de um "jeito" (teko) singular. É menos o sexo e mais esse nome-caminho que distingue as qualidades que a pessoa desenvolverá no futuro, pontua a autora.

Tratando de um contexto etnográfico muito diverso, o artigo de Diego Rosa Pedroso sobre a onomástica dos Cubeo - mais especificamente dos grupos Yuremawa e Yurinawa - , do alto Rio Negro, chega a conclusões semelhantes às de Aranha em relação aos nomes Guarani Mbya. Para os Cubeo, também, nomes fazem pessoas, são parte de pessoas e não apenas modos de representá-las ou classificá-las. Como resume Pedroso: "O pupui amiya ["nome tradicional", na tradução de alguns de seus principais interlocutores], assim entendido, aponta uma política onomástica que supõe uma concepção agentiva da linguagem, na qual nomes provenientes de personagens míticos operam sobre a vitalidade-energia (umé) que anima os seres humanos, conformam pessoas e determinam capacidades e habilidades." Aqui também o nome é atribuído por um “avô" - idealmente o pai do pai da criança. Mas, diferentemente do que se passa entre os Guarani, deve ser escolhido de um estoque limitado de nomes dos ancestrais do grupo, com base em cálculos relativos à ordem de nascimento do nomeado e características que se pretende propiciar na pessoa, ligadas à história do personagem mítico que figura na origem de cada nome. Assim como no caso Guarani, os nomes cubeo estão associados a certos caminhos, antecipados para o nomeado pelo próprio ato de nomeação. No caso rio-negrino, contudo, o processo é fortemente associado à marcação de relações assimétricas, associadas tanto à ordem de nascimento, quanto à identificação do nomeado a certas especialidades (xamã, guerreiro etc). Isso nos remete a uma potência da palavra notada por Gibram nas falas de aconselhamento kaingang: o nome cubeo, como as "leis" kaingang, tem a capacidade de produzir-atualizar diferenças significativas ao seu mundo.

Pedroso ilumina também o lugar dos apelidos, "nomes de brincadeira" (yahui amiya), entre os Cubeo. Na medida em que pronunciar um nome equivale a mobilizar ou tornar vulnerável uma parte da pessoa, o manejo dos nomes - como todo manejo da palavra - requer mediações: em alguns contextos, "brincar" é mais apropriado do que "falar sério"; em outros, o silêncio é a melhor opção. Como explica Pedroso, diferentemente do que se passa com os "nomes tradicionais", apelidos são frequentemente usados como referência a alguém pelos Cubeo. Uma pessoa pode colecionar apelidos, que vêm, em sua maioria, de animais, mas também de plantas, espíritos e instrumentos musicais. O autor sugere que seu uso diz muito sobre as relações supostamente hierárquicas, relações que os Cubeo preferem denominar, em seu próprio português, "de respeito" ou "de consideração". Não se pode usar, por exemplo, apelidos para se dirigir aos mais velhos, tampouco no jurupari, ritual de iniciação. Estes são empregados em situações amistosas, como aquelas que se desenrolam nas festas de caxiri, em que abundam comida e bebida. Daí a ideia mesma de "brincadeira”: o que fazem estes nomes são a alegria e a vitalidade. 
Fechando o dossiê, Antonio Guerreiro e Marina Novo apresentam reflexões sobre a relação entre poética e política no kuambü, festa de máscaras realizada pelos Kalapalo, outro povo de língua karib do alto Xingu. Essas máscaras presentificam itseke ("hiper-seres", na tradução dos autores), mais especificamente os itseke de origem aquática. Como em outros povos do alto Xingu, a festa é parte do processo de cura de um adoecimento provocado pelo itseke, sendo a pessoa que adoeceu tornada "dona das máscaras". O que diferencia o kuambü de outras festa de itseke associadas a processos de adoecimento e dos grandes rituais de chefia alto-xinguanos é que apenas no primeiro opera-se com um repertório de cantos aberto à invenção, de composição individual, e que remetem a tensões próprias às relações cotidianas da aldeia. Esse repertório tematiza ora acusações ou defesas contra acusações de feitiçaria, ora relações amorosas e, eventualmente, relações com não-indígenas. São cantos que problematizam a socialidade cotidiana na aldeia, marcada por laços de afinidade e pela oscilação entre cooperação e conflito. Guerreiro e Novo dialogam com Marina Vanzolini, que traduz morezowagetu - versão aweti (povo alto-xinguano de língua tupi) do kuambü - por "debate". Para Vanzolini, trata-se do momento no qual assuntos escondidos, relativos ao domínio do parentesco e ao campo da feitiçaria, tornam-se alvo de discussão coletiva.

Os cantos do kuambü também envolvem as mulheres de uma maneira particular, fazendo-as figurar tanto como objeto ou destinatário principal dos cantos, quanto como enunciadoras, isto é, cantoras. Guerreiro e Novo veem aí um momento de transformação das relações de gênero que estaria diretamente associado ao uso da linguagem. Homens cantam publicamente rumores, publicizam a fofoca (tipo de fala atribuído às mulheres, sempre em contextos domésticos); ao passo que as mulheres falam abertamente, publicamente, sobre assuntos coletivos (algo que, nos grandes rituais, permanece restrito ao círculo masculino). Segundo os autores, isso tudo se dá em uma atmosfera na qual emoções, como raiva e ciúme, tornam-se exacerbadas, margeando conflitos. Os autores oferecem uma análise fina da estrutura formal dos cantos, que sempre são endereçados a alguém. Dentre outros elementos, iluminam o uso de marcadores epistêmicos, que enfatizam um contexto de ambiguidade e incerteza: um amante pode enfeitiçar, o chefe pode ser um inimigo.

Permeado por acusações de feitiçaria e intrigas amorosas, o kuambü revela toda uma micropolítica que se contrapõe à macropolítica dos grandes rituais intercomunitários, como o quarup, organizado em torno de figuras da chefia. Essa contraposição, como não poderia deixar de ser, passa pela linguagem: se os grandes rituais põem em cena falas e cantos altamente formalizados, o kuambü cede espaço para a invenção e para a improvisação. Em vez de insistir em descontinuidades, em diferenças extensivas, o kuambü opera com "intensidades infinitesimais" - permitindo mesmo uma atualização articular das relações de gênero. E, como salientam Guerreiro e Novo, essas intensidades não deixam de incidir sobre o campo da macropolítica. Vale destacar a passagem em que os autores analisam cantos que falam da chefia - seja como lamento pela desvalorização dos chefes pelos seus seguidores, seja como crítica a comportamentos supostamente inadequados de um chefe, que quiçá os aproximam de feiticeiros. Cabe lembrar, ainda, que o oferecimento da festa atribui prestígio a um potencial chefe, e que isso não se dá fora do domínio dos itseke. Em suma, micropolítica, macropolítica e cosmopolítica encontram-se emaranhadas nesse evento, que testa os limites da diplomacia. 
Note-se, por fim, que os Kalapalo dizem dessa festa - e não de qualquer outra que realizem - que ela "é como a política", "porque as pessoas 'discutem' e 'querem mostrar quem está certo’”. ${ }^{6}$ Estamos aqui diante de um esforço de tradução do termo "política", análogo àquele que vimos no início desta apresentação. Se o termo "política”, cuja etimologia remonta ao grego antigo, à polis, é de difícil transposição para o universo ameríndio, isso não nos impede - antropólogos, indígenas, antropólogos indígenas - de buscar aproximações, incorrendo em "equivocações controladas" (Viveiros de Castro 2004). E, no caso kalapalo, essa aproximação envolve mais uma vez um evento diplomático cosmopolítico marcado por um uso singular da linguagem, por sua vez atrelado a uma concepção singular de linguagem.

Paola Gibram é doutoranda no Programa de Pós-Graduação em Antropologia Social/USP e pesquisadora do Centro de Estudos Amerindios - CestA/USP

Marina Vanzolini é professora do Departamento de Antropologia - DA/USP e pesquisadora do Centro de Estudos Amerindios - CestA/USP

Renato Sztutman é professor do Departamento de Antropologia - DA/USP e pesquisador do do Centro de Estudos Ameríndios - CestA/USP.

\section{REFERÊNCIAS BIBLIOGRÁFICAS}

BLOCH, Maurice. 1975. "Introduction”. In: Political Language and Oratory in Traditional Society, ed. M. Bloch. Cambridge: Cambridge University Press.

CADOGAN, León. 1959. “Ayvu rapyta: textos míticos de los Mbyá-Guaraní del Guairá”. Boletim da Faculdade de Filosofia, Ciências e Letras da Universidade de São Paulo. n. 227: série Antropologia n. 5. CESARINO, Pedro. 2011. Oniska : poética do xamanismo na Amazônia. São Paulo : Perspectiva. CESARINO, Pedro. 2012. "A palavra política nas terras baixas sul-americanas : o papel dos diálogos cerimoniais”. Manuscrito apresentado no GT “Repensando a política nas terras baixas sul-americanas", 28a. Reunião Brasileira de Antropologia.

CLASTRES, Hélène. 2011. “De quoi parlent les indiens?”. In: Pierre Clastres, ed. M. Abensour e Kupiec (eds.) Paris: Sens \& Tonka.

CLASTRES, Hélène. 1975. La terre sans mal: prophétisme tupi. Paris: Seuil.

CLASTRES, Pierre. 1974a. La Société contre l'État: recherches d'anthropologie politique. Paris: Eds. de Minuit. CLASTRES, Pierre. 1974b. Le Grand parler: chants sacrés des indiens Guarani. Paris: Seuil.

6 A comparação das festas com a nossa ideia de política é algo que Beatriz Perrone-Moisés (2015) encontra no discursos de outros interlocutores indígenas. Em seu belo estudo comparativo, ela propõe que as políticas indígenas sejam pensadas numa oscilação entre a festa e a guerra, entre o fazer e o desfazer de coletivos. Uma vez que as festas indígenas cedem espaço não raro a discursos de boas vindas, diálogos cerimoniais, cantos, entre outras manifestações da linguagem, podemos concluir que a proposta que aqui apresentamos é complementar à de Perrone-Moisés. Importante atentar que se os usos da linguagem nesses contextos são associados à evitação do conflito, sabemos que eles também o tangenciam. Uma acusação de feitiçaria, como se dá no caso do kuambü kalapalo, pode produzir cisões. A relação entre o uso da linguagem e a guerra é, infelizmente, um tema que não poderemos desenvolver aqui. Para uma análise da relação entre festa/ritual e usos da linguagem, ver o artigo de síntese de Rupert Stasch (2011). 
COURSE, Magnus. 2010. "Of words and fog : linguistic relativity and amerindian ontology". Anthropological Theory 10(3): 247-263.

COURSE, Magnus. 2011. "O nascimento da palavra: linguagem, força e autoridade ritual mapuche”. Revista de Antropologia 54(1): 781-827.

COURSE, Magnus. 2018. "Words beyond meaning in Mapuche language ideology”. Language \& Communication 63: 9-14.

DELEUZE, Gilles \& GUATTARI, Félix. 1980. Mille plateaux: capitalisme et schizophrénie II. Paris, Eds. de Minuit.

FARAGE, Nádia. 1997. As flores da fala: práticas retóricas entre os Wapixana. Tese de doutorado. São Paulo: USP.

GIRARDI, Luisa. 2019. Corpos da Terra: crescimento, movimento e relação segundo os Katxuyana. Tese de doutorado, Programa de Pós-graduação em Antropologia Social, Universidade de São Paulo. GRAHAM, Laura. 1993. "A public sphere in Amazonia? The depersonalized collaborative construction of discourse in Xavante". American Ethnologist 20(4): 717-741.

GRAHAM, Laura.1995. Performing Dreams: Discourses of Immortality among the Xavante of Central Brazil. Austin: University of Texas Press.

HAUCK, Jan D. 2018. “The origin of language among the Aché”. Language \& Communication 63: 76-88. HAUCK, Jan D. \& HEURICH, Guilherme O. 2018. "Language in the Amerindian imagination: An inquiry into linguistic natures". Language \& Communication 63: 1-8.

HEURICH, Guilherme O. 2018. "Reporting, capturoing and voicing speech amongst the Araweté". Language \& Communication 63:49-56.

KELLY, José Antonio. 2017. "On Yanomami cerimonial dialogues: a political aesthetic of metamorphical agency”. Journal de la Société des Américanistes 131(1): 179-214.

LATOUR, Bruno. 2007. “Quel cosmos? Quelles cosmopolitiques?” In: L'émergence des cosmopolitiques, ed. J. Lolive e O. Soubeyran. Paris: La Découverte.

LÉVI-STRAUSS, Claude. 1955. Tristes Tropiques. Paris: Plon.

MACEDO, Valeria. 2009. Nexos da diferença: cultura e afecção em uma aldeia guarani na Serra do mar. Tese de doutorado, Programa de Pós-graduação em Antropologia Social, Universidade de São Paulo. PERRONE-MOISÉS, Beatriz. 2015. Festa e guerra. Tese de Livre Docência. São Paulo: FFLCH-USP. RANCIÈRE, Jacques. 1995. La Mésentente: politique et philosophie. Paris: Galilée.

RUMSEY, Alan. 2009. “L'anthropologie a-t-elle besoin de sa proper pragmatique?”. In: Paroles en Actes, ed. C. Severi e J. Bonhomme. Cahiers d'Anthropologie Sociale. Paris: LAS.

SEVERI, Carlo \& BONHOMME, Julien (eds.). 2009. Paroles en Actes. Cahiers d'Anthropologie Sociale. Paris: LAS.

SILVERSTEIN, Michael. 2005. “The Poetics of Politics: 'Theirs' and 'Ours'”. Journal of Anthropological Research 61(1): 1-24.

STASCH, Rupert. 2011. "Ritual oratory revisited: the semiotics of effective action". Annual Review of Anthropology 40: 159-174

STENGERS, Isabelle. 2007. “La proposition cosmopolitique”. Pp. 45-68 in (eds.). L'émergence des 
cosmopolitiques, ed. J. Lolive e O. Soubeyran. Paris: La Découverte,.

VIVEIROS DE CASTRO, Eduardo. 2004. "Perspectival anthropology and the method of controlled equivocation". Tipiti 2(1): Article 1. 
Resumo: Este texto é uma breve apresentação do dossiê Diplomacias cosmopolíticas e os desafios da linguagem: perspectivas das terras baixas sul-americanas. Os artigos aqui reunidos apresentam como tema geral a relação entre política e linguagem no mundo ameríndio e abarcam não apenas a função de comunicação ou significação da linguagem, mas suas propriedades pragmáticas, sua eficácia no fazer, agir sobre o mundo. Este dossiê é um desdobramento do Seminário "Lições de Fala", ocorrido em julho de 2018 na USP, para o qual pesquisadores indígenas e não-indígenas reuniram-se para refletir e conversar sobre o que, segundo diferentes povos indígenas, falar quer dizer.

Palavras-chave: Linguagens indígenas; políticas ameríndias; diplomacias cosmopolíticas; lições de fala.

\section{COSMOPOLITICAL DIPLOMACY AND THE CHALLENGES OF LANGUAGE: SOUTH AMERICAN LOWLANDS PERSPECTIVES}

Abstract: This text is a brief presentation of the Cosmopolitical diplomacy and the challenges of language: South American lowlands perspectives dossier. The articles gathered here present as a general theme the relationship between politics and language in the Amerindian world and encompass not only the function of communication or meaning of language, but its pragmatic properties, its effectiveness in doing, acting on the world. This dossier is an extension of the "Lições de Fala" Seminar, held in July 2018 at USP, for which indigenous and non-indigenous researchers met to reflect and talk about what, according to different indigenous peoples, speaking means.

Keywords: Indigenous languages; amerindian politics; cosmopolitical diplomacy; speech lesson.

RECEBIDO: $03 / 11 / 2020$

APROVADO: $04 / 11 / 2020$ 
20 CAMPOS V21 N.1 p. 09-19 jan.jun. 2020 